\title{
ASSESSMENT OF MAXIMUM POWER POINT TRACKING TECHNIQUES FOR PV SYSTEM APPLICATIONS
}

\author{
Mohamed A. Farahat*, Mohamed A. Enany*, Ahmed Nasr* \\ * Department of Electrical power and machines, Faculty of Engineering, Zagazig University
}

\begin{abstract}
PV energy is one of the most important renewable energies because it is clean, requires very little maintenance. However, the relatively high costs and low conversion efficiency are still the major challenge to a larger and faster spread of PV systems. Therefore, the maximum power point tracker (MPPT) is essential in a PV system for maximizing the conversion efficiency of the solar array. Because of the nonlinear behavior of PV systems, various techniques of MPPT are employed in order to continuously operate the PV array at their MPP despite the unavoidable changes in solar irradiance and temperature. This paper presents an assessment of five widely used MPPT techniques. These techniques are simulated in Matlab/Simulink environment in order to provide a comparison in terms of sensors required, ease of implementation, efficiency and the dynamic response of the PV system to variations in temperature and irradiance to determine appropriateness for the different applications of PV system. This can be used as a reference for future research related to PV power generation.

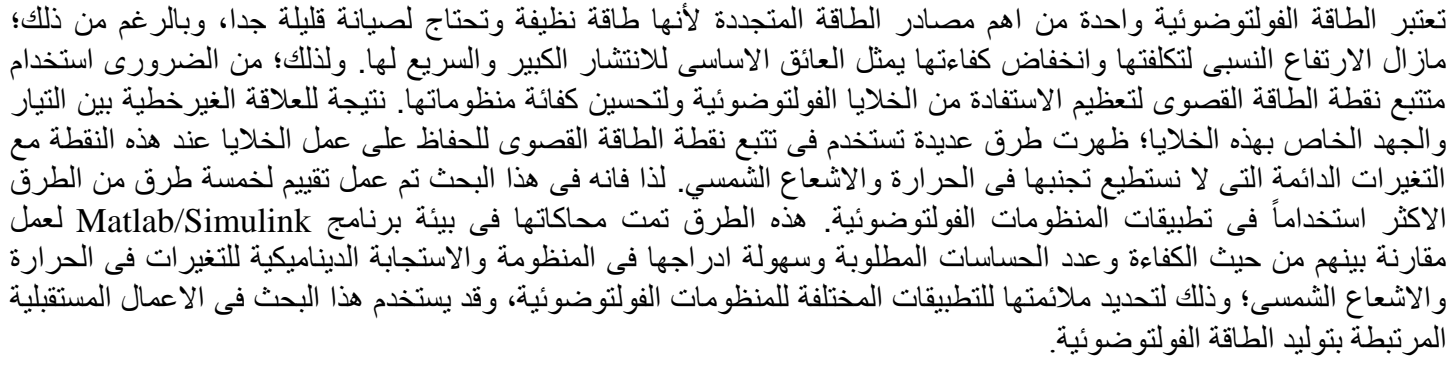

Keywords: MPPT techniques, Photovoltaic system (PV), Perturb and Observe (P\&O), Incremental Conductance (IncCond) and Fuzzy Logic Control (FLC).

\section{INTRODUCTION}

There is no doubt about it that the future world energy supply must be a mixture of many different sources, with a growing share of renewable energy. The main reasons that make the photovoltaic systems play a key role in this issue are the production of the electrical energy close to where it is required so that transport expenditure and energy losses can be avoided, no greenhouse gas emission, low maintenance cost and no noise because it do not require any moving parts [1]. The main applications of PV systems are in solar vehicles, water pumping, street lighting, remote areas electrification and space stations [3]. However, there are many drawbacks of PV systems: nonlinear behavior, the variation of the maximum power point with the climatic conditions which complicates the tracking task, low conversion efficiency which is less than 17\% [2]; and high installation cost. So, it becomes necessary to use MPPT system in order to ensure the efficient operation of the solar array. MPPT is a switch-mode power converter can be used for extracting the maximum power despite the continuous changes in irradiance and temperature by the control technique which adjusts the power and achieves its greatest possible value [5]. Several MPPT techniques have proposed in literature such as Fractional open circuit voltage technique [6], Perturb and Observe $(\mathrm{P} \& \mathrm{O})$ technique $[8,15]$, Incremental Conductance (IncCond) technique [14], Fuzzy Logic Control (FLC) based technique [16] and Temperature measurement based techniques $[11,20]$. These techniques vary in

Engineering Research Journal, Vol. 38, No.2, April 2015, PP: 127-136. 
complexity, sensors required, convergence speed, ease of implementation, popularity, and in other respects. This paper presents a careful assessment for five MPPT techniques, using models in Matlab/Simulink environment, with a brief discussion in order to provide a reference for the future works related to the design of PV systems. The rest of this paper is organized as follows: section II introduces MPPT system overview; Section III describes the main MPPT techniques; Section IV presents the obtained simulation results and discusses the different techniques. Finally, conclusions are contained in section V.

\section{SYSTEM OVERVIEW}

PV systems consist of PV panels, DC-DC converters, control technique and loads. A typical operation of MPPT system is depicted in Fig. 1, where the measured values of the output voltage and/or current of the PV panel are fed to the MPPT technique which updates the duty cycle $(D)$ of the DC-DC converter to maximize the power delivered to the load [10].

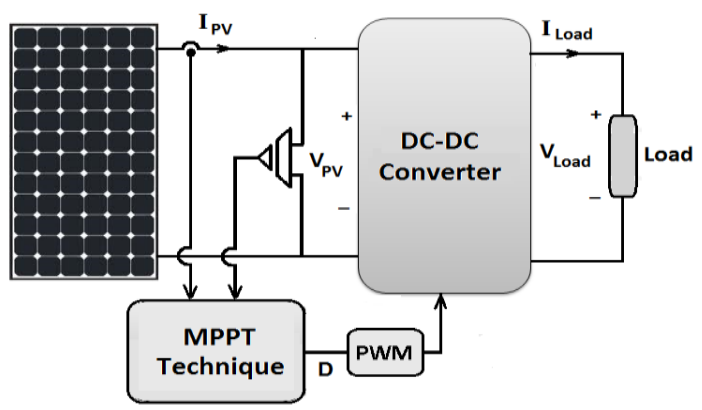

Fig. 1. Implementation of MPPT system.

\section{A. PV model:}

The PV panel is composed of several PV cells connected in series or parallel or both. The equivalent circuit of the single-diode model for PV cells is shown in Fig. 2. The most commonly used expression of the output current $I_{P V}$ and output voltage $V_{P V}$ of a PV panel with $N_{S}$ cells in series and $N_{P}$ strings in parallel based on the single exponential model is found from Eq. (1) which describes the current-voltage characteristics of a PV module [6].

$$
\begin{aligned}
& I_{P V} \\
& =N_{p} I_{S C}-N_{p} I_{o}\left[\exp \left(\frac{q\left(V_{P V}+I_{P V} \frac{N_{s}}{N_{p}} R_{s}\right)}{N_{s} n K T}\right)-1\right] \\
& -\frac{V_{P V}+I_{P V} \frac{N_{s}}{N_{p}} R_{s}}{\frac{N_{s}}{N_{p}} R_{p}}
\end{aligned}
$$

where $I_{s c}$ is the light generated PV current, $I_{o}$ is the reverse saturation current, $n$ is the diode ideality factor, $q$ is the charge of electron, $K$ is the Boltzmann constant, $T$ is the cell temperature, and $R_{S}, R_{P}$ are the series and parallel equivalent resistances of the solar cell respectively.

The main electrical parameters of SM55 PV module used are summarized in Appendix A. The currentvoltage characteristics, shown in Fig. 3, demonstrate that the maximum power point (MPP) of the PV module is influenced by the irradiance $(G)$ and temperature $(T)$ changes and show that either the PV voltage or PV current can represent this point.

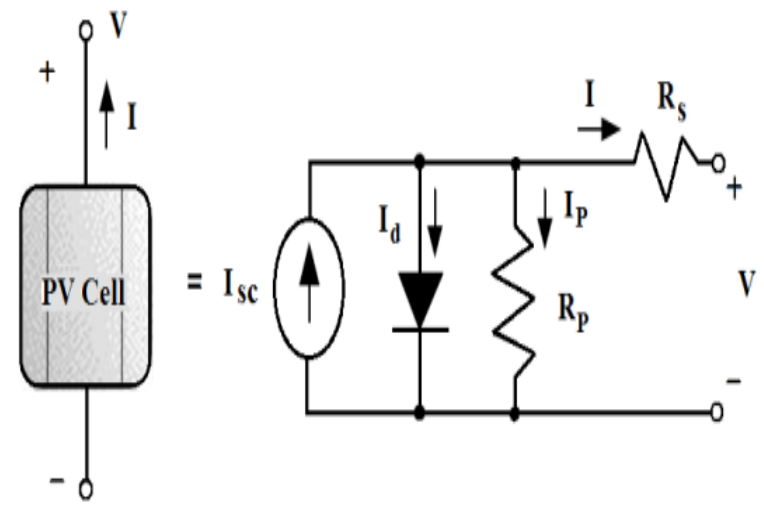

Fig. 2. Equivalent circuit of a PV cell using the single exponential model. 


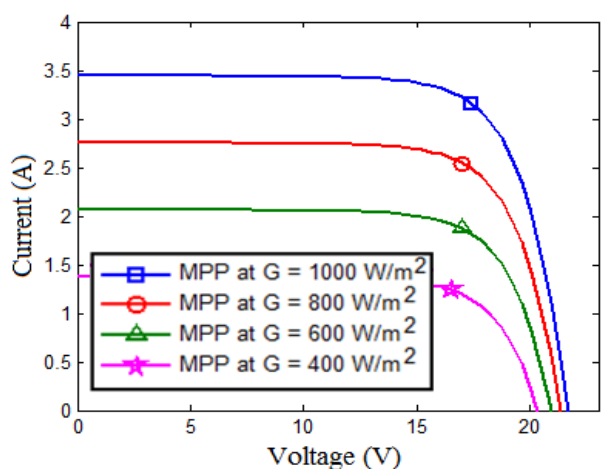

(a)

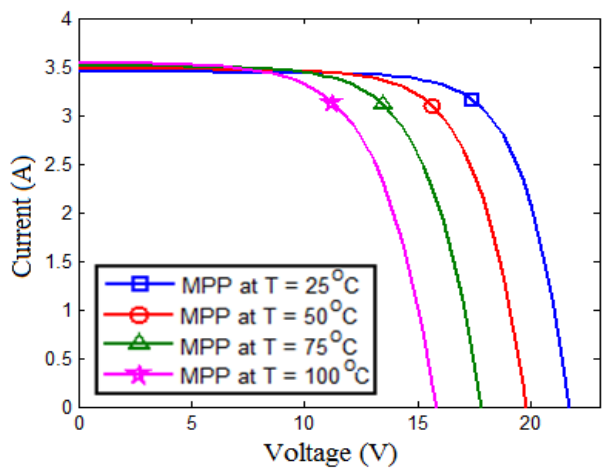

(b)

Fig. 3. Simulated I-V curves of a specific solar module, SM55, (a) at different irradiance at $25{ }^{\circ} \mathrm{C}$, (b) at different temperature at $1000 \mathrm{~W} / \mathrm{m}^{2}$.

At a certain operating condition, the control of the MPPT regulates the voltage or current to a value that represent the MPP. The PV voltage regulation is preferred over the PV current regulation due to the following reasons [4]:

- Measuring the voltage signal is cheaper and easier than that of the current.

- The voltage of the MPP is within a certain range, about $65 \%$ to $82 \%$ of the open circuit voltage.

- The voltage of the MPP is affected slightly by changes in the irradiance.

- The cell temperature is the major factor that affects the voltage of the MPP; however, it has slow dynamics and is always within a certain range.

\section{B. DC-DC Converter:}

DC-DC converter is used for matching the characteristics of the load with those of the PV panel and regulating the PV voltage by varying the duty cycle using MPPT technique in order to maintain the operating point at the MPP of the PV panel. DC-DC converters are classified into many types: boost converters, buck converters, buck-boost converters and ćuk converter. The performance parameters of each type can be described by: voltage gain $\left(A_{v}\right)$, boundary filter inductance $\left(L_{b}\right)$ and minimum filter capacitance $\left(C_{\min }\right)$ [9]. These parameters can be calculated using the relationships which are summarized in Appendix A. Boost DC-DC converter, shown in Fig. 4, is chosen in the present work because its sensitivity to small changes in D is larger than buck and buck-boost converter [9].

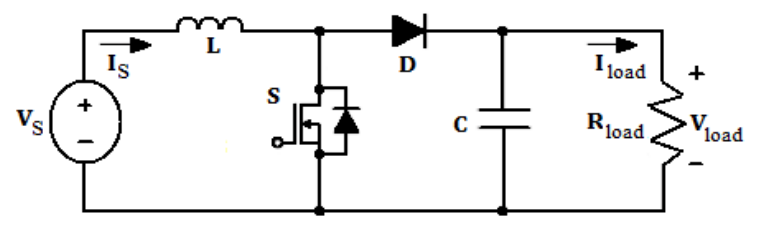

Fig. 4. Circuit diagram of boost DC-DC converter.

\section{MAIN MPPT TECHNIQUES}

\section{A. Modified fractional OC voltage technique:}

Fractional open circuit (OC) voltage is one of the simplest MPPT techniques because it is based on the approximately linear relationship between the voltage at MPP $\left(V_{M P P}\right)$ and the open circuit voltage $\left(V_{o c}\right)$ of the $\mathrm{PV}$ panel under varying irradiance and temperature levels as described by the following equation:

$$
V_{M P P} \cong K_{1} \times V_{o c}
$$

where $K_{l}$ is proportionality constant, which depends on the characteristics of the PV panel being used. This constant has to be computed in advance by determining $V_{M P P}$ and $V_{o c}$ for the specific PV panel at different irradiance and temperature levels [14]. The value of $K_{1}$ ranges from 0.63 and 0.8 for SM55 PV module over a temperature range of $25-75{ }^{\circ} \mathrm{C}$ and irradiance levels from 200 to $1000 \mathrm{~W} / \mathrm{m}^{2}$ as shown in Fig. 5.

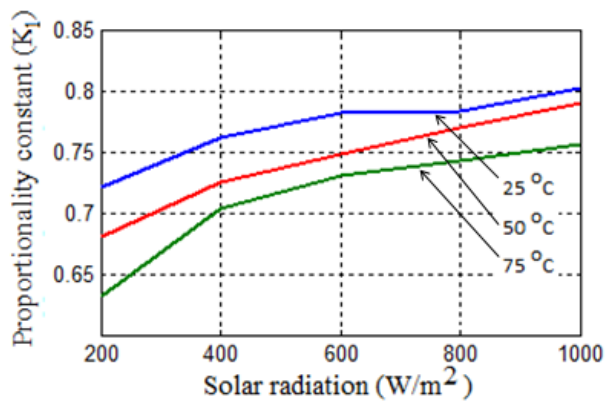

Fig. 5. $V_{M P P}$ as a percentage of $V_{O C}$ as functions of irradiance and temperature.

Once $K_{l}$ is known and $V_{o c}$ is measured periodically by momentarily isolating the power converter, $V_{M P P}$ can be calculated using Eq. (2) and it can be reached by a 
closed loop control loop on the power converter [5]. Although this method is very easy and cheap to implement as it needs a single voltage sensor and doesn't require microcontroller control, it has two major drawbacks. First, The MPP reached is not the real one because Eq. (2) is only an approximation and depends on difficult choice of the optimal value of the constant $K_{l}$. Second, the power supplied to the load is lost due to periodic isolation of the power converter in order to measure $V_{o c}$ [6]. So, the modified fractional open circuit voltage technique is used to overcome the loss of power problem by measuring the temperature and irradiance in order to calculate $\mathrm{V}_{\mathrm{oc}}$ using the following equations [13]:

$$
\begin{aligned}
& \boldsymbol{V}_{\boldsymbol{o c}} \\
& =\boldsymbol{C}_{\boldsymbol{T V}} \boldsymbol{C}_{\boldsymbol{G V}} \boldsymbol{V}_{\boldsymbol{o c}}^{S T C} \\
C_{T V} & =1+\frac{K_{V}}{V_{O C}^{S T C}}(T-25) \\
C_{G V} & =1+\beta_{T} \alpha_{G}(G-1000)
\end{aligned}
$$

where $C_{T V}$ is the variation of $\mathrm{V}_{\mathrm{oc}}$ with temperature, $\boldsymbol{V}_{\boldsymbol{o c}}^{\boldsymbol{S T C}}$ is the open circuit voltage at standard test conditions - STC $\left(1000 \mathrm{~W} / \mathrm{m}^{2}, 25{ }^{\circ} \mathrm{C}\right), K_{v}$ is the temperature coefficient of $\mathrm{V}_{\mathrm{oc}}$ (it is taken $-0.077 \mathrm{~V} /{ }^{\circ} \mathrm{C}$ for SM55 PV module), $C_{G V}$ is the variation of $\mathrm{V}_{\mathrm{oc}}$ with solar irradiance, $\boldsymbol{\alpha}_{\boldsymbol{G}}=\Delta \boldsymbol{T} /(\boldsymbol{G}-\mathbf{1 0 0 0})$ and $\Delta T$ is the temperature change due to change in irradiance. The values of $\boldsymbol{\beta}_{\boldsymbol{T}}$ and $\boldsymbol{\alpha}_{\boldsymbol{G}}$ taken are 0.0016 and 0.006 respectively.

Once $V_{o c}$ is calculated, $V_{M P P}$ can be determined using Eq. (2) and it can be reached using PI controller which minimize the error between the output voltage of the PV panel and $V_{M P P}$ by adjusting the duty cycle of the power converter.

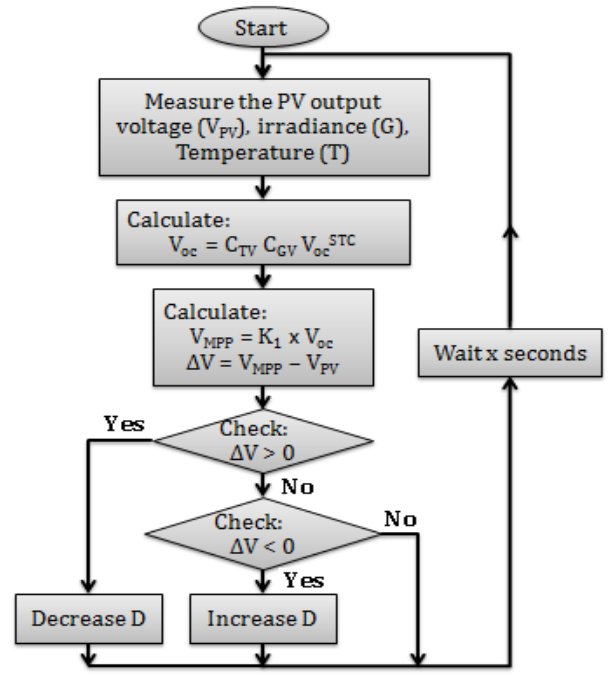

Fig. 6. Flow chart of Modified fractional open circuit voltage technique.
Fig. 7 validates the simulation of the modified open circuit voltage method according to the flow chart depicted in Fig. 6.

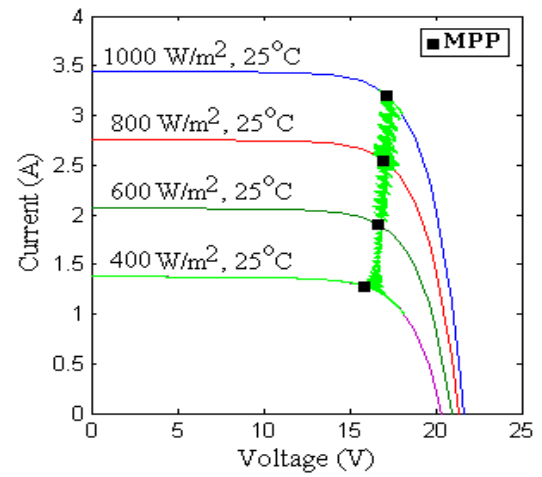

Fig. 7. Tracing of MPP using modified open circuit voltage technique.

\section{B. Perturb and Observe $(\mathrm{P} \& O)$ technique:}

This method is based on periodical perturbing (increasing or decreasing) the PV panel's terminal voltage or the switching duty cycle in order to change the system operating point and then observing the output power variation $(\Delta \mathrm{P})$. If the power increases ( $\Delta \mathrm{P}$ is positive), the MPP will be approached, therefore the perturbation should be kept the same for the following stage; otherwise the perturbation should be reversed. This process is repeated until the MPP is reached [14]. Fig. 9 validates the simulation of the $\mathrm{P} \& \mathrm{O}$ MPPT technique according to the flow chart depicted in Fig. 8. The main features of this MPPT technique is its simplicity and ease of implementation as it requires two sensors to measure the PV panel voltage and current [14]. However, P\&O (or hill climbing) has two fundamental defects. First, it has oscillations around the MPP because of the perturbation process. This oscillation can be minimized by reducing the perturbation step size but the tracking speed will be reduced. To overcome this problem a modified adaptive hill climbing (MAHC) is proposed in [15] to avoid tracking deviation and improve its performance by making the perturbation step size of the switching duty cycle large during transient stage and small in steady state. In [16], fuzzy logic control is used for optimizing the perturbation step size. Second, it fails to track the MPP during rapidly changes in atmospheric conditions because it is not able to determine whether the change in the power is due to its own voltage perturbation or due to the change in the irradiance levels. This defect has been treated in [17]. 


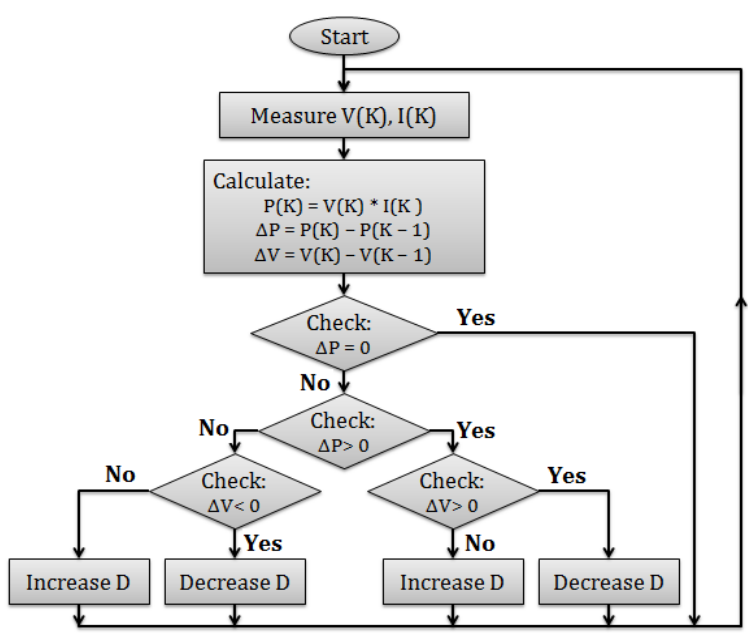

Fig. 8. Flow chart of $\mathrm{P} \& \mathrm{O}$ technique.

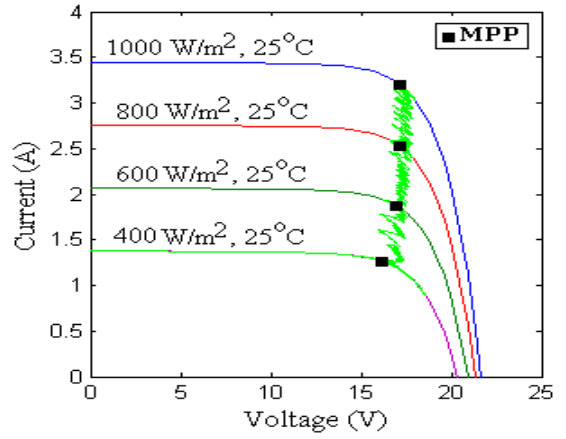

Fig. 9. Tracing of MPP using $\mathrm{P} \& \mathrm{O}$ technique.

\section{Incremental conductance (IncCond) technique:}

It is one of the MPPT techniques which are based on the fact that the slope of the PV panel's power-voltage characteristics $(d P / d V)$, represented by Eq. (6), is zero at the MPP as shown on Fig. 10.

$$
\begin{gathered}
\frac{d P}{d V}=\frac{d(I V)}{d V}=I+V \frac{d I}{d V}=0 \rightarrow \frac{d I}{d V}=-\frac{I}{V} \text { at } M P P \\
\frac{d P}{d V}>0 \rightarrow \frac{d I}{d V}>-\frac{I}{V} \text { left of } M P P \\
\frac{d P}{d V}<0 \rightarrow \frac{d I}{d V}<-\frac{I}{V} \text { right of } M P P
\end{gathered}
$$

where $(-I / V)$ is the reverse of the instantaneous conductance and $(\boldsymbol{d} \boldsymbol{I} / \boldsymbol{d} \boldsymbol{V})$ is the incremental conductance of the PV panel.

Hence, from the voltage and current measurements, the algorithm calculates the PV panel's instantaneous conductance and its incremental conductance to decide if the duty cycle of the converter $D$ should be increased or decreased according to equations (6), (7) and (8) for tracking the MPP as shown in Fig. 10.

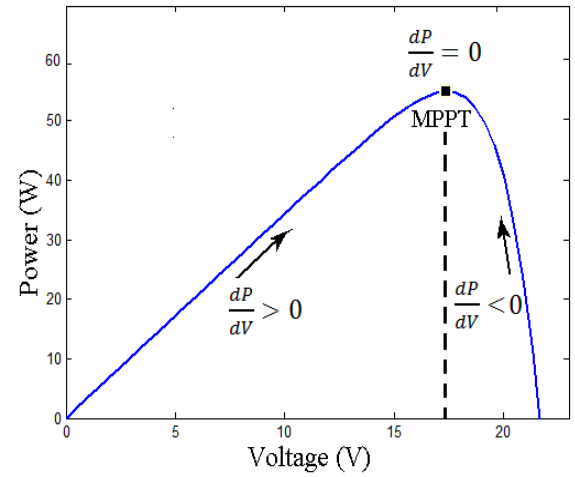

Fig. 10. The power-voltage characteristics of a PV panel.

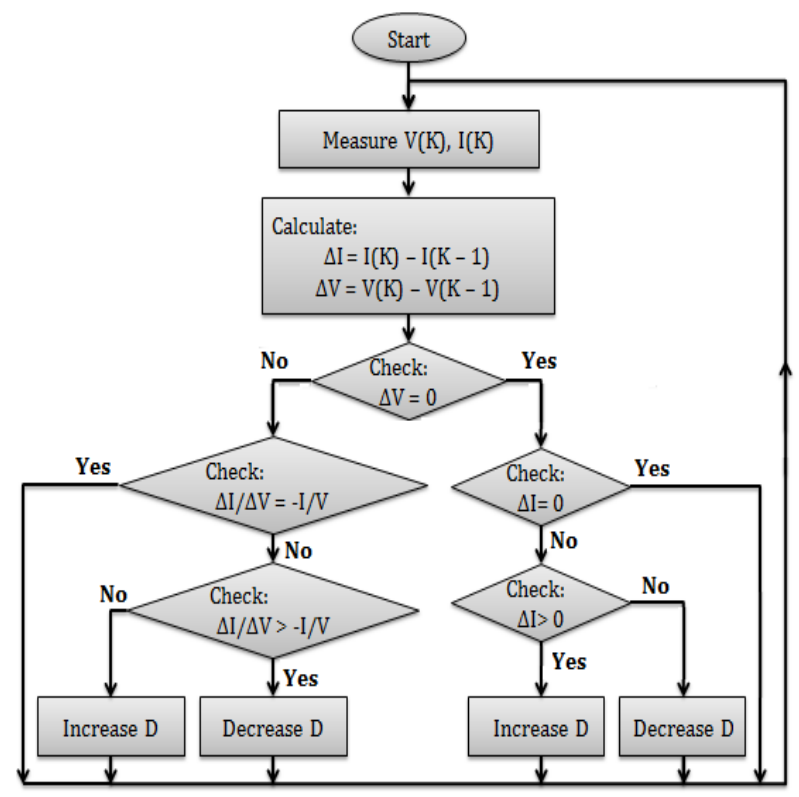

Fig. 11. Flow chart of IncCond MPPT technique [8]. A large step size of the increment or decrement improves the tracking speed but negatively affect the oscillations around the MPP in steady state. The main advantage of IncCond over the $\mathrm{P} \& \mathrm{O}$ technique is that it is presents better transient performance when subjected to rapidly changes in atmospheric conditions [5], [14]. The dynamic response can be improved using PI controller which provides a dynamic step size for the duty cycle of the power converter depending on the error between the reverse of the instantaneous conductance the incremental conductance of the PV panel. Fig. 12 validates the simulation of the IncCond MPPT technique in Simulink according to the flow chart depicted in Fig. 11. 


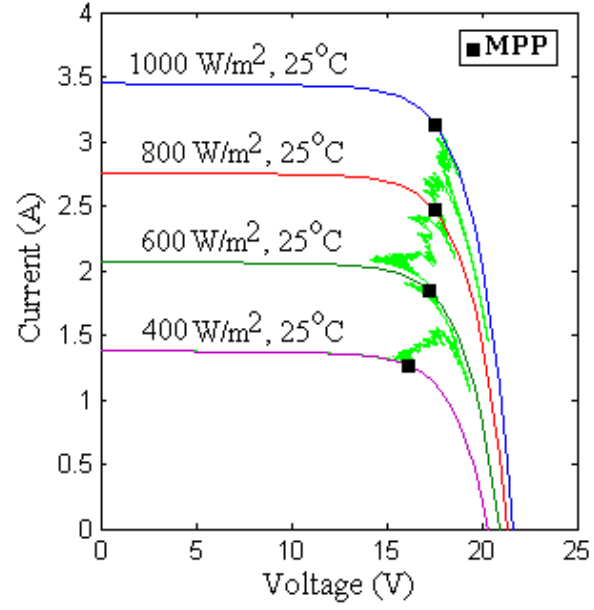

Fig. 12. Tracing of MPP using IncCond technique.

\section{Fuzzy logic control (FLC) based MPPT technique:}

Fuzzy logic controllers have occupied a high position for tracking the maximum power point over the last decades because of its simplicity, its ability to handle nonlinearity, fast convergence, capability of dealing with imprecise inputs and doesn't need accurate mathematical model [14, 16, 19].

Fuzzy logic control consists of three stages: fuzzification, decision-making and defuzzification as depicted in Fig. 13. During fuzzification stage, the numerical crisp inputs are transformed to linguistic variables based on a membership function like the ones in Fig. 14. The number of membership functions used depends on the accuracy of the controller, but it usually varies between five and seven. In the decision making stage, the rules which are specified by a set of IF-THEN statements, depending on the power converter being used, defines the behavior of the controller. In the defuzzification stage, the fuzzy logic controller output is transformed from linguistic variable to a numerical crisp variable still using a membership function [10].

In this work, the inputs of the fuzzy logic controller are chosen to be the change of the PV output power $\Delta \mathrm{P}$ and the change of the output voltage $\Delta \mathrm{V}$ which are defined by Eq. (9) and (10) and the output is the increment of the duty cycle of the power converter $\Delta \mathrm{D}$ as proposed in [16]. Seven fuzzy levels are used for e ach variable: NB (negative big), NM (negative medium), NS (negative small), ZE (zero), PS (positive small), PM (positive medium), PB (positive big).

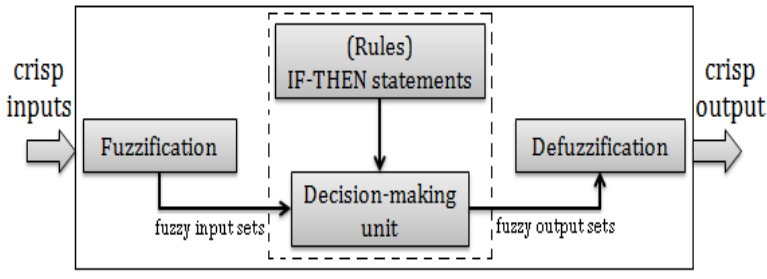

Fig. 13. The basic Configuration of fuzzy logic controller.

$$
\begin{aligned}
& \Delta P=P(K)-P(K-1) \\
& \Delta V=V(K)-V(K-1)
\end{aligned}
$$

Once $\Delta P$ and $\Delta V$ are calculated and converted to linguistic variables, the fuzzy logic controller output $\Delta \mathrm{D}$ can be looked up in a rule base table such as Table 1 , which is proposed for the boost converter used in this work. These rules are based on the fact that if the change in the voltage causes the power to increase, the moving of the next change is kept in the same direction otherwise the next change is reversed. For example, if the operating point is far to the right of the

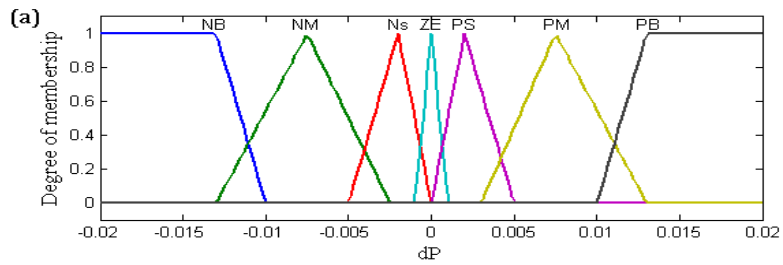

(b)

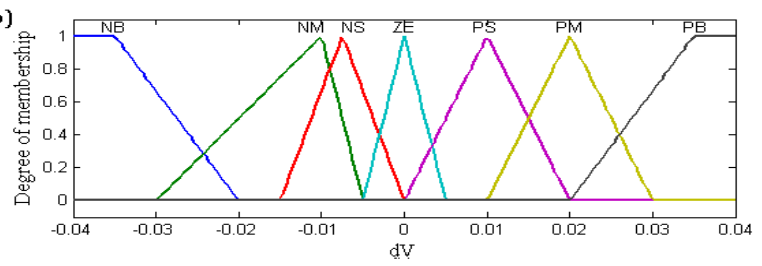

(c)

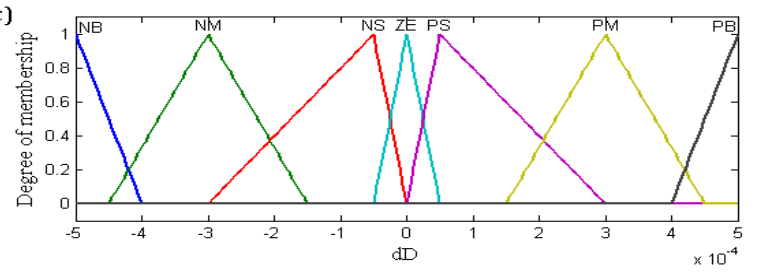

Fig. 14. The membership function of (a) The input variable $\Delta \mathrm{P} ; \quad$ (b) The input variable $\Delta \mathrm{V}$; (c) The output variable $\Delta \mathrm{D}$.

$\mathrm{MPP}, \Delta \mathrm{P}$ is NB , and $\Delta \mathrm{V}$ is $\mathrm{PS}$, then to reach the MPP the duty cycle should increase, so $\Delta \mathrm{D}$ should be $\mathrm{PB}$ (Positive) to move the operating point towards the MPP. Rapid changing solar irradiance is taken into account while designing these rules. Fig. 15 validates the simulation of FLC based MPPT technique. 
TABLE 1

Rule Base Used In The Fuzzy Logic Controller

\begin{tabular}{|c||c|c|c|c|c|c|c|}
\hline$\Delta \mathbf{P}$ & NB & NM & NS & ZE & PS & PM & PB \\
\hline \hline NB & NS & NM & NS & PS & PS & PM & PS \\
\hline NM & NM & NS & NM & PS & PM & PS & PM \\
\hline NS & NB & NB & NS & PS & PS & PB & PB \\
\hline ZE & PB & PB & PB & PS & NB & NB & NB \\
\hline PS & PE & PM & PS & NS & NS & NM & NB \\
\hline PM & PM & PS & PM & NS & NM & NS & NM \\
\hline PB & PS & PM & PS & NS & NS & NM & NS \\
\hline
\end{tabular}

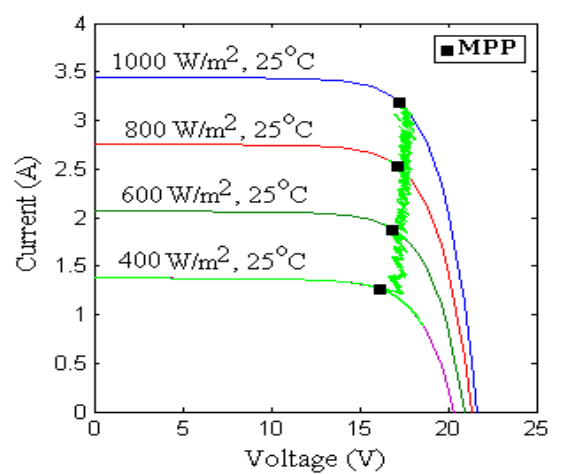

Fig. 15. Tracing of MPP using FLC based MPPT technique.

\section{E. Temperature measurement based MPPT technique:}

This technique is based on the fact that the PV output voltage is directly proportional to the temperature on the PV surface. In [20], two different temperature techniques are available. The first one is the temperature gradient (TG) technique which uses the temperature to determine the open-circuit voltage $V_{o c}$ from Eq. (11) and then calculate the optimal voltage $V_{M P P}$ as in the fractional open circuit voltage technique. The second one is the temperature parametric equation (TP) technique which adopts the optimal voltage Eq. (12) and determines $V_{M P P}$ instantaneously by measuring the temperature $(T)$ and the solar irradiance $(G)$.

$$
\begin{gathered}
V_{O C}=V_{O C}^{S T C}+K_{V}(T-25) \\
V_{M P P}=[(u+G \times v)-T(w+G \times y)] V_{M P P}^{S T C}
\end{gathered}
$$

where $u, v, w$ and $y$ are the parameters of the optimal voltage equation that depends on the irradiance level.

In [11], a simple temperature technique called MPPTtemp is proposed. In this technique, the current sensor is substituted by a temperature sensor fixed on the PV back surface. The system starts measuring the PV output voltage $V_{P V}$ and temperature $T$ then evaluates the $V_{M P P}$ by (13) and depending on the difference between the measured value of the PV output voltage
$V_{P V}$ and the desired maximum power point voltage $V_{M P P}$, the duty cycle $D$ is updated in order to keep the $\mathrm{PV}$ output voltage as close as possible to $V_{M P P}$.

$$
V_{M P P}=V_{M P P}^{S T C}+u_{v}(T-25)
$$

where $\boldsymbol{V}_{\boldsymbol{M P P}}^{S T C}$ is the maximum power point voltage at standard test conditions $\left(1000 \mathrm{~W} / \mathrm{m}^{2}, 25{ }^{\circ} \mathrm{C}\right)$ and $u_{v}$ is the temperature coefficient of $V_{M P P}$ (PV panel's datasheet information). The main features of this technique are its ease of implementation, simplicity, fast tracking and no steady state oscillation around the MPP. Fig. 17 validates the simulation of the temperature measurement based MPPT technique in Simulink according to the flow chart depicted in Fig. 16.

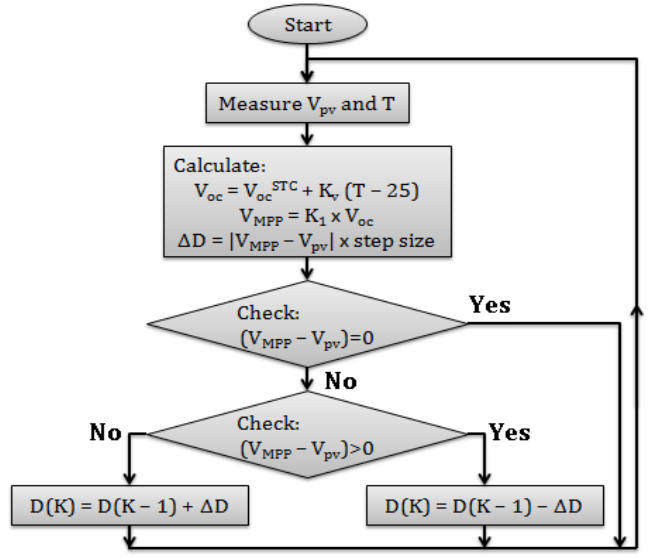

Fig. 16. Flow chart of temperature measurement based MPPT technique.

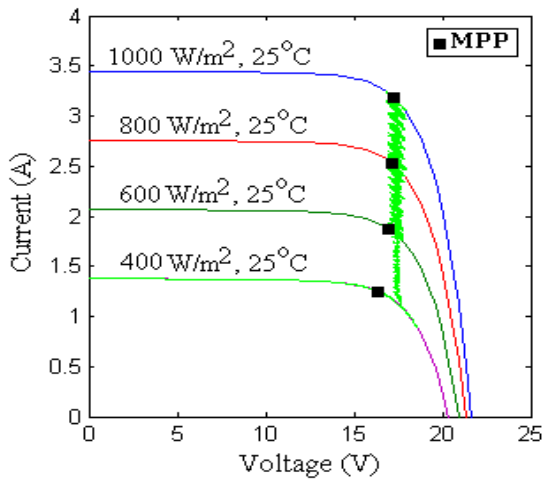

Fig. 17. Tracing of MPP using temperature measurement based MPPT technique.

\section{SIMULATION RESULTS AND DISCUSSION}

In this section, the simulations were performed on a PV system for comparing the MPPT techniques. The PV system used in the simulations is shown in Fig. 18. This system consists of SM55 solar module which provides a maximum power of $55 \mathrm{~W}$. The input of 


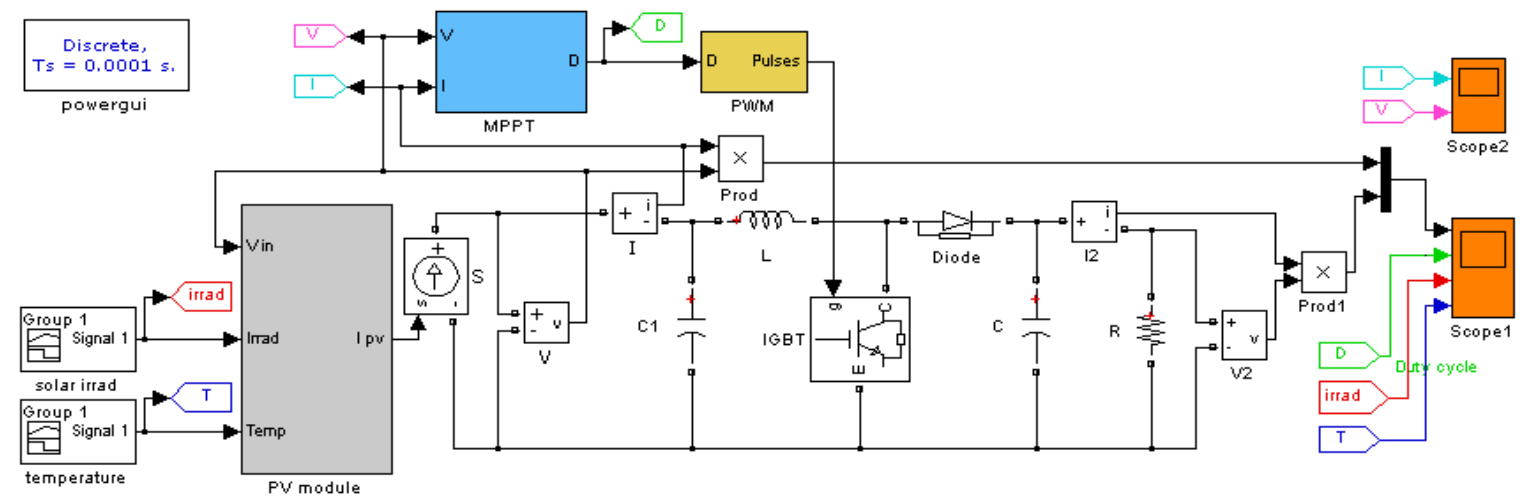

Fig. 18. Configuration of the PV system in Simulink environment.

the power converter is connected to the PV panel, the output is connected to the resistive load and the control signal generated by each MPPT technique fed to a PWM for controlling the boost converter's switching MOSFET. The system was simulated in Matlab/Simulink software environment. Different types of changes in the solar irradiance and temperature are used during the simulation to test the MPPT techniques at different operating conditions: step changes (Fig. 19a) and ramp changes (Fig. 19b).

The simulation results indicates that the modified fractional open circuit voltage technique, the IncCond technique, the FLC based technique as well as the temperature based technique are all able to track the MPP for fast changes in the solar irradiance and temperature but the P\&o technique fails to do that as depicted in Fig. 19b. As mentioned above, the accuracy of the modified fractional open circuit voltage technique and the temperature based technique suffers as a result of the difficult choice of the optimal value of the constant $K_{l}$ however; they have the best convergence speed as depicted in Fig. 19a. Furthermore, the P\&o technique has the worst tracking speed and it can be improved by increasing the perturbation step size.

The efficiency of the MPPT technique is a very important consideration for special PV system applications such as the power supply used in space stations and satellites. It can be determined by the following equation [6]:

$$
=\frac{1}{n} \sum_{i=0}^{n} \frac{\boldsymbol{P}_{\boldsymbol{i}}}{\boldsymbol{P}_{\max , i}}
$$

where $P_{i}$ is the PV output power, $P_{\max }$ is the maximum power and $n$ is the number of samples.

The simulation results indicated that the FLC based technique as well as the modified fractional OC voltage has the best efficiency as compared to the other techniques.

The ease of implementation of the MPPT technique has a large impact on the overall cost of the PV system. Whether the MPPT technique is an analog or digital implementation and the sensor requirements are important factors specifying its ease of 
implementation. The analog implementation is easier and cheaper than the digital one as it doesn't need microcontroller and programming. As a result, the $\mathrm{P} \& \mathrm{O}$ technique, as well as the temperature measurement based technique is easier and cheaper than the other techniques because they can be implemented in an analog manner and need double sensors. The characteristics of the simulated MPPT techniques are summarized in Table 2.
The results indicate that the modified fractional OC voltage technique, the FLC based technique and the IncCond technique provide an excellent tracking performance independently on the climatic conditions. The temperature measurement based technique is characterized by its simplicity of implementation but it has the lowest efficiency because of its bad accuracy. Finally, the performance of the $\mathrm{P} \& \mathrm{O}$ technique depends on the perturbation step size.

This simulation based assessment can be useful in specifying the appropriateness of the MPPT techniques for the different PV system applications.

(a)

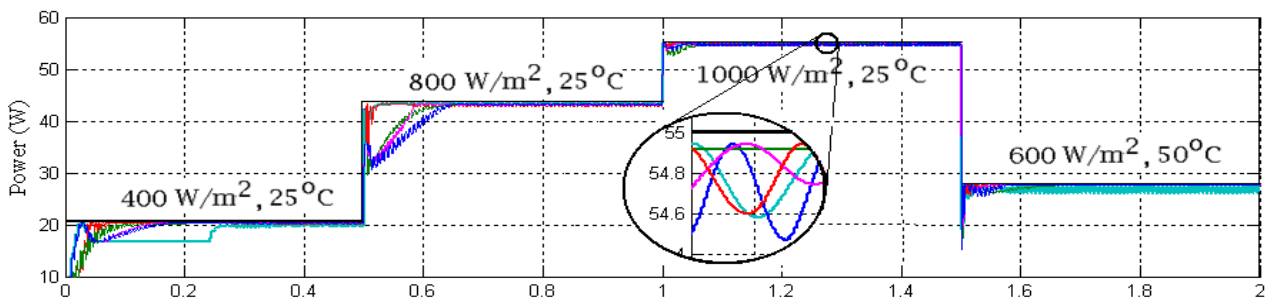

(b)

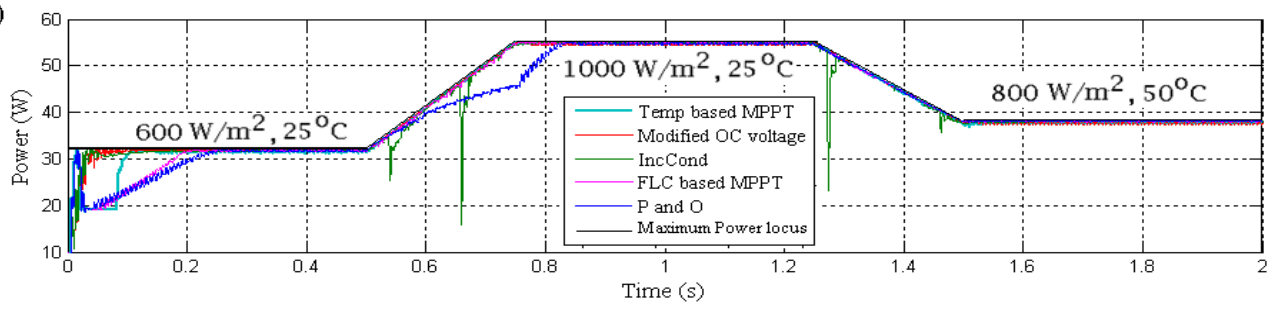

Fig. 19. The PV output power in changes of irradiance and temperature: (a) step changes, (b) ramp changes

TABLE 2

The Characteristics of The MPPT TeChNiQues

\begin{tabular}{|c||c||c||c||c|}
\hline $\begin{array}{c}\text { MPPT } \\
\text { technique }\end{array}$ & $\begin{array}{c}\text { Convergence } \\
\text { speed }\end{array}$ & Efficiency & $\begin{array}{c}\text { Digital } \\
\text { or } \\
\text { Analog }\end{array}$ & $\begin{array}{c}\text { Number } \\
\text { of sensors }\end{array}$ \\
\hline \hline $\begin{array}{c}\text { Modified } \\
\text { fractional } \\
\text { OC voltage }\end{array}$ & Fast & $98.46 \%$ & Both & 3 \\
\hline FLC & Fast & $98.1 \%$ & Digital & 2 \\
\hline IncCond & Medium & $97.6 \%$ & Digital & 2 \\
\hline P\&O & Low & $97.5 \%$ & Both & 2 \\
\hline $\begin{array}{c}\text { Temperature } \\
\text { technique }\end{array}$ & Fast & $96.2 \%$ & Both & 2 \\
\hline
\end{tabular}

\section{CONCOLUSION}

In this work, the most widely used MPPT techniques have been assessed according to simulations in Matlab/ Simulink environment based on the dynamic response of the PV system, the tracking speed of convergence, the efficiency and the ease of implementation.
The electrical parameters of the SM55 PV Module are shown in Table A.1.

TABle A.1

Electrical Parameters Of The SM55 PV Module.

\begin{tabular}{|c||c|}
\hline Maximum power rating $P_{\max }$ & $55 \mathrm{~W}$ \\
\hline \hline Rated current $I_{M P P}$ & $3.15 \mathrm{~A}$ \\
\hline \hline Rated voltage $V_{M P P}$ & $17.4 \mathrm{~V}$ \\
\hline \hline Short circuit current $I_{S C}$ & $3.45 \mathrm{~A}$ \\
\hline \hline Open circuit voltage $V_{O C}$ & $21.7 \mathrm{~V}$ \\
\hline \hline Temperature coefficient of $I_{S C}$ & $1.2 \mathrm{~mA} /{ }^{\circ} \mathrm{C}$ \\
\hline \hline Temperature coefficient of $V_{O C}$ & $-0.077 \mathrm{~V} /{ }^{\circ} \mathrm{C}$ \\
\hline
\end{tabular}

The DC-DC boost converter under study is operating at $10 \mathrm{kHz}$, a filter inductance of $2 \mathrm{mH}$, a filter capacitor of $1000 \mu \mathrm{F}$ and a resistive load of $20 \Omega$ with electrical parameters are shown in Table A.2. 
TABLE A.2

Performance PARAMETERs For DC-DC BoOst CONVERTER

\begin{tabular}{|c||c|}
\hline$A_{V}$ & $\frac{1}{1-D}$ \\
\hline \hline$L_{b}$ & $\frac{(1-D)^{2} D R_{\text {Load }}}{2 f}$ \\
\hline \hline$C_{\text {min }}$ & $\frac{D V_{\text {Load }}}{V_{r} R_{\text {Load }} f}$ \\
\hline
\end{tabular}

\section{REFERENCES}

[1] Gilbert M. Masters, "Photovoltaic Materials and Electrical Characteristics," in Renewable and Efficient Electric Power Systems, Ed. New Jersey: John Wiley \& Sons, 2004, pp. 445- 500.

[2] Messenger, Roger and Jerry V., "Photovoltaic Systems Engineering", 2nd Edition, CRC Press, 2003.

[3] "Tends In Photovoltaic Applications", Report IEAPVPS, 2010.

[4] Weidong Xiao, Elnosh A., Khadkikar V., and Zeineldin H., "Overview of maximum power point tracking technologies for photovoltaic power systems", IECON 2011 - 37th Annual Conference on IEEE industrial electronics society, pp. 3900-5, 2011.

[5] Esram T. and Chapman PL., "Comparison of photovoltaic array maximum power point tracking techniques", Energy Conversion, IEEE Transactions on vol. 22, pp. 439-449, 2007.

[6] D. P. Hohm and M .E. Ropp, "Comparative Study of Maximum Power Point Tracking Algorithms", Prog. Photovolt: Res. Appl, volume 11, pp. 47-62, 2003.

[7] H. Tiana, F. Mancilla-David, K. Ellis, E. Muljadic, and P. Jenkinsd, "A cell-to-module-to-array detailed model for photovoltaic panels," Solar Energy, pp. 2695- 2706, 2012.

[8] de Brito M. A. G., Galotto L., Sampaio L. P., de Azevedo e Melo G.; Canesin C. A.," Evaluation of the Main MPPT Techniques for Photovoltaic Applications", IEEE Transaction on Industrial Electronics, Vol. 60, Issue 3, pp. 1156-1167, 2013.

[18] Ninth IEEE Photovoltaic Specialists Conference, pp. 1531-34, 2002.

[19]Zhou Dejia, Zhao Zhengming, Mohamed Eltawil, Yuan Liqiang, "Design and control of a three-phase grid-connected photovoltaic system with developed maximum power point tracking", Twenty-Third Annual IEEE Applied Power Electronics Conference and Exposition (APEC), pp. 973-9, February 24-28, 2008.

C. Larbes, S.M. Cheikh, T. Obeidi, A. Zerguerras, " $[r \cdot$ Genetic algorithms optimized fuzzy logic control for the maximum power point tracking in photovoltaic
[9] M. A. Farahat, H. M. B. Metwally, Ahmed A. Mohamed, "Optimal choice and design of different topologies of DC-DC converter used in PV systems, at different climatic conditions in Egypt", Renewable Energy, Vol. 43, pp. 393-402, 2012.

[10] Ali Reza Reisi, Mohammad Hassan Moradi, Shahriar Jamasb, "Classification and comparison of maximum power point tracking techniques for photovoltaic system: A review", Renewable and Sustainable Energy Reviews, Vol. 19, pp. 433-443, 2013.

[11] Roberto F. Coelho, Filipe M. Concer, Denizar C. Martins, "A MPPT Approach Based on Temperature Measurements Applied in PV Systems", 9th IEEE/IAS International Conference on Industry Applications, 2010.

[12]Bidyadhar Subudhi and Raseswari Pradhan, "A Comparative Study on Maximum Power Point Tracking Techniques for Photovoltaic Power Systems", IEEE Transaction on Sustainable Energy, Vol. 4, 2013.

[13] Sayal A., "MPPT techniques for photovoltaic system under uniform insolation and partial shading conditions", Proceedings of 2012 students conference on engineering and systems (SCES), pp.1-6, 2012.

[14]M. A. Eltawil, Z. Zhao, "MPPT techniques for photovoltaic applications," Renewable and Sustainable Energy Reviews, Vol. 25, pp. 793-813, 2013.

[15] W. Xiao, W. G. Dunford, “A modified adaptive hill climbing MPPT method for photovoltaic power systems", $35^{\text {th }}$ annual IEEE power electronics specialists conference, pp. 1957-63, 2004.

[16] A. M. Noman, K. E. Addoweesh and H. M. Mashaly, "A Fuzzy Logic Control Method for MPPT of PV Systems", IECON - 38th Annual Conference on IEEE Industrial Electronics Society, pp. 874-80, 2012.

[17] G.J. Yu, Y.S. Jung, J.Y. Choi, G.S. Kim, “A novel two-mode MPPT control algorithm based on comparative study of existing algorithms", Twenty-

system”, Renewable Energy, Vol. 34, Issue 19, pp. [Y'] 2093-2100, 2009.

[22] Roberto Faranda, Sonia Leva, "A Comparative Study of MPPT techniques for PV Systems", 7th WSEAS International Conference on Application of Electrical Engineering (AEE'08), Trondheim, Norway, July 2-4, 2008, pp. 100-105.

[23] Siemens, Siemens Solar Module SM55, Siemens Solar GmbH, 1998. 